\title{
Local Regulation of Neurofilament Transport by Myelinating Cells
}

\author{
Paula C. Monsma, ${ }^{1}$ Yinyun Li, ${ }^{2}$ J. Daniel Fenn, ${ }^{1}$ Peter Jung, ${ }^{2}$ and Anthony Brown ${ }^{1}$ \\ ${ }^{1}$ Department of Neuroscience, Ohio State University, Columbus, Ohio 43210, and ${ }^{2}$ Quantitative Biology Institute, Ohio University, Athens, Ohio 45701
}

\begin{abstract}
Axons in the vertebrate nervous system only expand beyond $\sim 1 \mu \mathrm{m}$ in diameter if they become myelinated. This expansion is due in large part to the accumulation of space-filling cytoskeletal polymers called neurofilaments, which are cargoes of axonal transport. One possible mechanism for this accumulation is a decrease in the rate of neurofilament transport. To test this hypothesis, we used a fluorescence photoactivation pulse-escape technique to compare the kinetics of neurofilament transport in contiguous myelinated and unmyelinated segments of axons in long-term myelinating cocultures established from the dorsal root ganglia of embryonic rats. The myelinated segments contained more neurofilaments and had a larger cross-sectional area than the contiguous unmyelinated segments, and this correlated with a local slowing of neurofilament transport. By computational modeling of the pulse-escape kinetics, we found that this slowing of neurofilament transport could be explained by an increase in the proportion of the time that the neurofilaments spent pausing and that this increase in pausing was sufficient to explain the observed neurofilament accumulation. Thus we propose that myelinating cells can regulate the neurofilament content and morphology of axons locally by modulating the kinetics of neurofilament transport.
\end{abstract}

Key words: axonal transport; cell culture; cytoskeleton; fluorescence microscopy; myelination; neurofilament

\section{Introduction}

Two basic mechanisms by which animals increase axonal conduction velocity are to increase axonal caliber and to insulate axons by myelination (Waxman, 1980; Hartline and Colman, 2007). Intriguingly, it has been known since the 1930s that in the vertebrate nervous system most unmyelinated axons do not exceed $\sim 1 \mu \mathrm{m}$ in diameter, whereas most myelinated axons grow much larger (Duncan, 1934; Matthews, 1968; Matthews and Duncan, 1971), and this relationship is also recapitulated in cell culture (Windebank et al., 1985). Moreover, when myelinated axons in the CNS or PNS are unmyelinated along part of their length, axonal crosssectional area is reduced locally in the unmyelinated segments (Bray et al., 1981; Pannese et al., 1988; Witt and Brady, 2000). Thus, the expansion of axonal caliber during development is dependent on myelination and this appears to be a local effect.

The principal determinants of the expansion of axonal caliber in vertebrates are neurofilaments, which are the intermediate filaments of nerve cells (Cleveland et al., 1991; Hoffman, 1995; Perrot and Eyer, 2010). The space-filling properties of neurofilaments are maximized by side-arm projections which protrude from the polymer backbone and function to keep adjacent neurofilaments at arm's length (Hisanaga and Hirokawa, 1988; Mukhopadhyay et al., 2004). Morphometric studies have established a direct correlation between neurofilament number and axonal

Received Oct. 22, 2013; revised Jan. 4, 2014; accepted Jan. 7, 2014.

Author contributions: P.J. and A.B. designed research; P.C.M. and J.D.F. performed research; P.C.M., Y.L., J.D.F., P.J., and A.B. analyzed data; P.J. and A.B. wrote the paper.

This work was supported by NIH Grant R01 NS 038526 to A.B. and collaborative NSF Grants IOS 1146809 and IOS 1146789 to A.B. and P.J., with additional support provided by NIH P30 Grant NS 045758. We thank Roger Tsien of the University of California San Diego for the mCherry.

The authors declare that they have no competing financial interests.

Correspondence should be addressed to Dr. Anthony Brown, Department of Neuroscience, Ohio State University, Rightmire Hall, 1060 Carmack Road, Columbus, 0H 43210. E-mail: brown.2302@0su.edu.

DOI:10.1523/JNEUROSCI.4502-13.2014

Copyright $\odot 2014$ the authors $\quad 0270-6474 / 14 / 342979-10 \$ 15.00 / 0$ cross-sectional area, and in large axons these space-filling polymers occupy most of the axonal volume (Friede and Samorajski, 1970; Friede et al., 1971; Hsieh et al., 1994; Nixon et al., 1994; Sanchez et al., 1996, 2000). Axons in mutant animals that lack neurofilaments fail to develop normal caliber and exhibit reduced conduction velocities (Sakaguchi et al., 1993; Perrot et al., 2007; Zhu et al., 1997).

Despite their structural role, neurofilaments are also cargoes of axonal transport. These polymers move rapidly in both anterograde and retrograde directions, but their net velocity is slow because they spend most of their time pausing (Brown, 2000, 2003; Roy et al., 2000; Wang et al., 2000; Brown et al., 2005). Thus, the balance of movements and pauses determines the average velocity and, consequently, the total residence time of these polymers in the axon. In a series of papers published in the 1980s, Hoffman and colleagues proposed that the radial expansion of axons during development and regeneration is caused in part by a slowing of neurofilament transport (Hoffman et al., 1983, 1984, Hoffman et al., 1985a,b). According to this hypothesis, a decrease in the velocity of neurofilament transport would be expected to cause neurofilaments to accumulate, leading to an expansion of axonal caliber, perhaps analogous to the increase in traffic density on a highway when the speed of the vehicles slows. To test this hypothesis, we have analyzed the kinetics of neurofilament transport in long-term myelinating cocultures from rat dorsal root ganglia using live-cell imaging.

\section{Materials and Methods}

Cell culture. Mixed cocultures of Schwann cells and DRG neurons were established from E16.5 rat embryos according to the method of Fex Svenningsen et al. (2003) with some modifications, as described by Monsma and Brown (2012). Briefly, the cells were trypsinized, dissociated by trituration, and plated onto glass-bottomed dishes coated with poly-Dlysine and Matrigel (BD Biosciences) at a density of 2000-12,000 cells/ $\mathrm{cm}^{2}$. The cultures were maintained at $37^{\circ} \mathrm{C} / 5 \% \mathrm{CO}_{2}$ in Neurobasal medium supplemented with 2\% B27 supplements (Invitrogen Life Technologies), 2 
mM L-glutamine, and $100 \mathrm{ng} / \mathrm{ml}$ nerve growth factor (BD Biosciences). Five days after plating the cells, the medium was replaced with fresh medium containing a 1:100 dilution of Matrigel, and 3 d later, half of this medium was removed and replaced with fresh medium containing $50 \mu \mathrm{g} / \mathrm{ml}$ ascorbic acid. The cultures were maintained for up to 3 months, replacing half the medium with fresh medium containing $50 \mu \mathrm{g} / \mathrm{ml}$ ascorbic acid every 2-3 d, with a full medium change once each week.

Constructs and transfection. The pmCherry expression construct was obtained by subcloning mCherry (Shaner et al., 2004) in place of the EGFP sequence in pEGFP-C1 (Clontech; Alami et al., 2009). The pEGFPrat neurofilament $\mathrm{M}$ expression construct (pEGFP-NFM) has been described by Wang et al. (2000). The cultures were cotransfected with pmCherry and pEGFP-NFM (ratio 0.3:1) after 4-6 weeks in culture using Lipofectamine 2000 (Life Technologies) cationic lipid reagent in Opti-MEM medium (Life Technologies) according to the manufacturer's instructions. Fortuitously, we found that neurons were transfected under these conditions, whereas Schwann cells were not. The neuronal transfection efficiency was low (typically $\sim 6-12$ neurons per dish), but this was not a problem because each neuron formed an extensive axonal arbor.

Staining with FluoroMyelin Red. The use of FluoroMyelin Red as a vital stain for live imaging of myelin has been described by Monsma and Brown (2012). FluoroMyelin Red in aqueous solution was purchased from Invitrogen (Life Technologies, catalog \#F34652, lot no. 23512W) and stored in the dark at $4^{\circ} \mathrm{C}$. To stain the cultures, we first removed the culture medium and rinsed once with observation medium consisting of a low fluorescence formulation of Hibernate-EB medium (Hibernate-EB LF; BrainBits) supplemented with $100 \mathrm{ng} / \mathrm{ml} 2.5 \mathrm{~S}$ nerve growth factor. We then added fresh observation medium containing FluoroMyelin Red (1:300 dilution) and placed the cultures in an incubator at $37^{\circ} \mathrm{C}$ with atmospheric $\mathrm{CO}_{2}$. After $2 \mathrm{~h}$, we withdrew the medium and replaced it with fresh observation medium lacking FluoroMyelin Red.

Inhibition of glycolysis. To inhibit glycolysis, we first stained with FluoroMyelin Red and then replaced the observation medium with fresh observation medium containing $2 \mathrm{~mm}$ sodium iodoacetate (SigmaAldrich), which is an inhibitor of glyceraldehyde-3-phosphate dehydrogenase (Schmidt and Dringen, 2009). Pulse-escape experiments were performed in the presence of the inhibitor 13-100 min after the start of the treatment.

Microscopy and imaging. Cells were observed in observation medium by epifluorescence, phase contrast or differential interference contrast microscopy on a TE2000 inverted microscope (Nikon Inc.) using a Nikon 40 / 1.0 NA Plan Apo oil-immersion objective. For epifluorescence, we used ETEGFP and ET-mCherry filter sets (filter set numbers 49002 and 49008, respectively; Chroma Technology), and a custom-made FluoroMyelin Red filter set consisting of a D450/40 bandpass exciter, a 505dcxr dichroic mirror, and an E610LPv2 long-pass emission filter (Chroma Technology). The temperature on the microscope stage was maintained using an Air Stream Incubator (Nevtek). A layer of dimethylpolysiloxane fluid (Sigma, 5 centistokes) was floated over the observation medium to prevent evaporation. For live fluorescence imaging, the epi-illumination from the mercury arc lamp was attenuated 4-fold or 10-fold using neutral density filters, and images were acquired using a CoolSNAP HQ cooled CCD camera (Roper Scientific) and MetaMorph software (Molecular Devices).

Photoactivation. PAGFP (photoactivatable GFP) was photoactivated in user-defined regions of interest by illumination with violet light for 5-30 s using a Mosaic Digital Diaphragm (Andor Technology) equipped with a mercury arc lamp light source (Olympus America) and controlled using the Targeted Illumination drop-in in the MetaMorph software. The Digital Diaphragm illumination was introduced into the epi-illumination light path using a dichroic mirror that transmits in the violet spectrum $(385-450 \mathrm{~nm})$, and the light was directed to the specimen using a $495 \mathrm{~nm}$ long-pass dichroic mirror (Chroma Technology) in the microscope filter turret. The axial length of the activated regions along the axons was $10 \mu \mathrm{m}$.

Measurement of fluorescence intensities. The intensity of the activated PAGFP fluorescence was measured using MetaMorph software. A rectangular region of interest (ROI-1) was drawn manually around a segment of axon, encompassing its entire width. Additional flanking regions (ROI-2 and ROI-3) were drawn in the background on either side of the axon, taking care to avoid other fluorescent material or cells. The contri- bution of the background fluorescence to ROI-1 was calculated by multiplying the average pixel intensity in ROI-2 and ROI-3 by the area of ROI- 1 , and then this value was subtracted from the total fluorescent intensity in ROI-1 to yield the background-corrected intensity. The resulting background-corrected intensities were corrected for photobleaching. To calibrate the rate of photobleaching, we acquired images of the photoactivated PAGFP fluorescence in rapid succession and then quantified the fluorescence decay. The photobleaching kinetics were exponential, with a $1 \%$ loss per second of exposure using 4 -fold attenuation of the exciting light and a $0.4 \%$ loss per second of exposure using 10 -fold attenuation of the exciting light (data not shown).

Measurement of axonal caliber. Axon diameter was measured in live images of the GFP-tagged neurofilament protein fluorescence by creating linear intensity profiles along lines perpendicular to the axis of the axons, and then measuring the width of the profiles at half-height to the nearest pixel. For each myelinated or unmyelinated axonal segment, we calculated an average diameter from measurements made at a minimum of three independent locations. Cross-sectional areas were calculated from the average diameters by assuming that the axons were cylindrical in shape.

Mathematical modeling. In this section we describe how we deciphered the neurofilament transport kinetics from the fluorescence decay kinetics in the pulse-escape experiments. The underlying model (Jung and Brown, 2009) comprises six states (shown below in Fig. 7B): two states ( $a$ and $r$ ) in which the neurofilaments move either anterogradely or retrogradely, two states $\left(a_{0}\right.$ and $\left.r_{0}\right)$ in which the anterogradely and retrogradely moving neurofilaments pause briefly, and two states $\left(a_{\mathrm{p}}\right.$ and $\left.r_{\mathrm{p}}\right)$ in which the anterogradely and retrogradely moving neurofilaments pause for an extended time. We refer to the moving and short-term pausing states as "on-track" and the long-term pausing states as "offtrack" (Trivedi et al., 2007).

The set of equations describing this model are given by

$$
\begin{aligned}
& \frac{\partial \rho_{a}}{\partial t}=-v_{a} \frac{\partial \rho_{a}}{\partial x}-\gamma_{10} \rho_{a}+\gamma_{01} \rho_{a 0} \\
& \frac{\partial \rho_{r}}{\partial t}=-v_{r} \frac{\partial \rho_{r}}{\partial x}-\gamma_{10} \rho_{r}+\gamma_{01} \rho_{r 0} \\
& \frac{\partial \rho_{a 0}}{\partial t}=-\left(\gamma_{01}+\gamma_{a r}+\gamma_{\text {off }}\right) \rho_{a 0}+\gamma_{10} \rho_{a}+\gamma_{r a} \rho_{r 0}+\gamma_{\text {on }} \rho_{a p} \\
& \frac{\partial \rho_{r 0}}{\partial t}=-\left(\gamma_{01}+\gamma_{r a}+\gamma_{\text {off }}\right) \rho_{r 0}+\gamma_{10} \rho_{r}+\gamma_{a r} \rho_{a 0}+\gamma_{\text {on }} \rho_{r p} \\
& \frac{\partial \rho_{a p}}{\partial t}=-\left(\gamma_{\text {on }}+\gamma_{a r}\right) \rho_{a p}+\gamma_{\text {off }} \rho_{a 0}+\gamma_{r a} \rho_{r p} \\
& \frac{\partial \rho_{r p}}{\partial t}=-\left(\gamma_{\text {on }}+\gamma_{r a}\right) \rho_{r p}+\gamma_{\text {off }} \rho_{r 0}+\gamma_{a r} \rho_{a p},
\end{aligned}
$$

where the distribution of neurofilaments in the states " $\mathrm{x}$ " are denoted by $\rho_{\mathrm{x}}$.

At steady state, the proportions of the neurofilaments in each kinetic state are given by

$$
\begin{aligned}
& \rho_{a}=\frac{1}{1+q_{1}\left(1+q_{2}\right)} \frac{1}{1+q_{3}}, \rho_{r}=\frac{q_{3}}{1+q_{1}\left(1+q_{2}\right)} \frac{1}{1+q_{3}}, \\
& \rho_{a 0}=\frac{1}{1+q_{1}\left(1+q_{2}\right)} \frac{q_{1}}{1+q_{3}}, \rho_{r 0}=\frac{1}{1+q_{1}\left(1+q_{2}\right)} \frac{q_{1} q_{3}}{1+q_{3}}, \\
& \rho_{a p}=\frac{1}{1+q_{1}\left(1+q_{2}\right)} \frac{q_{1} q_{2}}{1+q_{3}}, \rho_{r p}=\frac{1}{1+q_{1}\left(1+q_{2}\right)} \frac{q_{1} q_{2} q_{3}}{1+q_{3}},
\end{aligned}
$$

where $q_{1}=\gamma_{10} / \gamma_{01}, q_{2}=\gamma_{\text {off }} / \gamma_{\text {on }}$, and $q_{3}=\gamma_{a r} / \gamma_{r a}$. 
The average velocity of the neurofilaments is determined by the balance of time spent in the anterograde and retrograde moving states (Jung and Brown, 2009), i.e.,

$$
\bar{v}=\rho_{a} v_{a}+\rho_{r} v_{r}=\frac{\left(v_{a}+q_{3} v_{r}\right)}{\left(1+q_{1}\left(1+q_{2}\right)\right)\left(1+q_{3}\right)},
$$

where $v_{a}$ and $v_{r}$ are the velocities of neurofilaments in the anterograde and retrograde moving states, respectively. This average velocity can be interpreted either as the velocity of one neurofilament averaged over a long time (time average), or as the average velocity of a large number of neurofilaments at a single point in time (ensemble average).

We have shown previously (Jung and Brown, 2009) that the average on-track and off-track pause durations $\left\langle T_{\text {off }}\right\rangle$ and $\left\langle T_{\text {on }}\right\rangle$ are given by

$$
\begin{gathered}
\left\langle T_{\text {off }}\right\rangle=\frac{1}{\gamma_{\text {on }}} \\
\left\langle T_{\text {on }}\right\rangle=\frac{1}{\gamma_{01}+\gamma_{\text {off }}} .
\end{gathered}
$$

To extract the rate constants of our model from the pulse-escape experiments, we simulate a pulse-escape experiment. Initially, all neurofilaments within a window of size $a$ are photoactivated. At this time, the activated neurofilaments are distributed over their kinetic states according to Equations 2. Subsequently, the neurofilaments leave the activation window, anterogradely and retrogradely, with a net flux given by $\rho_{a} v_{a}-$ $\rho_{r} v_{r}$. The initial decline of the fluorescence $Q$, normalized to unity at $t=$ 0 , then reads

$$
\frac{Q(t)}{Q(0)}=1-\frac{\rho_{a} v_{a}-\rho_{r} v_{r}}{Q(0)} t=1-\frac{\rho_{a} v_{a}-\rho_{r} v_{r}}{a} t,
$$

which can be written as

$$
\frac{Q(t)}{Q(0)}=1-\frac{1}{a} \frac{1-q_{3}\left(v_{r} / v_{a}\right)}{1+q_{3}\left(v_{r} / v_{a}\right)} \bar{v} t
$$

Published measurements of the average velocities of neurofilaments in their mobile states have ranged from $0.38 \mu \mathrm{m} / \mathrm{s}$ to $0.53 \mu \mathrm{m} / \mathrm{s}$ for $v_{a}$ and from $-0.49 \mu \mathrm{m} / \mathrm{s}$ to $-0.60 \mu \mathrm{m} / \mathrm{s}$ for $v_{r}$ (Wang et al., 2000; Wang and Brown, 2001; Uchida and Brown, 2004; Alami et al., 2009; Uchida et al., 2009). For the purposes of this analysis, we assume $v_{a}=0.5 \mu \mathrm{m} / \mathrm{s}$ and $v_{r}=-0.5 \mu \mathrm{m} / \mathrm{s}$, which simplifies the expression for the decline of the fluorescence given in Equation 6 to

$$
\begin{aligned}
\frac{Q(t)}{Q(0)} & =1-\frac{1}{a} \frac{1+q_{3}}{1-q_{3}} \bar{v} t=1-\frac{1}{a} \frac{1}{1+q_{1}\left(1+q_{2}\right)} v_{a} t \\
& \equiv 1-\alpha t,
\end{aligned}
$$

where $\alpha$ is the initial slope and is proportional to the average velocity. Once those neurofilaments that are initially in the mobile or short-term pausing states have left the window (which takes minutes), the population in the activated region shifts to one that is largely immobile and therefore not distributed according to Equations 2 anymore. Hence the rate of fluorescence decay slows down, and is now dictated largely by the transitions of photoactivated neurofilaments to the mobile states from the immobile states. Neglecting reversals, which are very infrequent on the time scale of our pulse-escape experiments (Brown et al., 2005), we expect that the fluorescence decay at long times will be exponential, i.e., $Q(t) / Q(0) \propto \exp \left(-\gamma_{d} t\right)$, with a rate constant given by

$$
\gamma_{d}=\gamma_{01} \frac{\beta+(1 / 2) \epsilon \kappa^{2}}{\delta+\kappa \beta \epsilon+(1 / 6) \kappa^{3} \epsilon^{2}}
$$
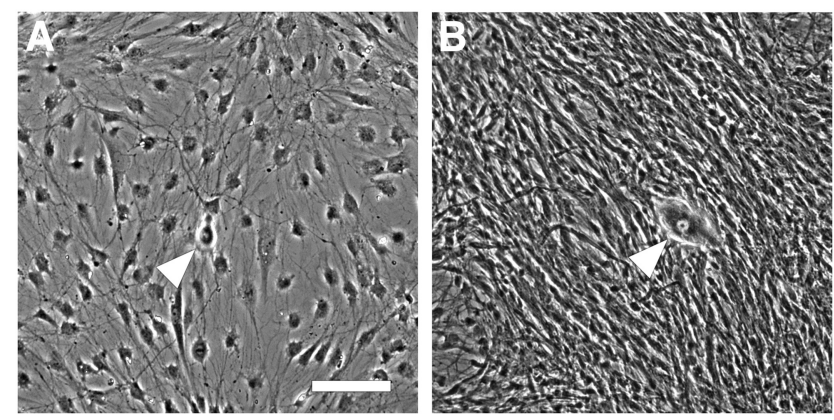

Figure 1. Mixed cocultures of Schwann cells and DRG neurons. A, Phase contrast image of a mixed coculture of Schwann cells and DRG neurons after $5 \mathrm{~d}$ in vitro, before addition of ascorbic acid. $\boldsymbol{B}$, Phase contrast image of the same culture after $27 \mathrm{~d}$ in vitro, $19 \mathrm{~d}$ after the addition of ascorbic acid. Each field contains a single neuronal cell body (white arrowheads) surrounded by many Schwann cells. The cell bodies enlarge considerably as the neurons mature. Scale bar, $100 \mu \mathrm{m}$.

where

$$
\begin{aligned}
& \epsilon=a \gamma_{10} / v_{a} \\
& \kappa=\left(1 / q_{1}\right)+1+q_{2} \\
& \beta=\left(1+q_{2}\right)^{2}+q_{2}\left(\gamma_{01} / \gamma_{\text {on }}\right) \\
& \delta=\left(1+q_{2}\right)^{3}+2 q_{2}\left(1+q_{2}\right)\left(\gamma_{01} / \gamma_{\text {on }}\right)+q_{2}\left(\gamma_{01} / \gamma_{\text {on }}\right)^{2} .
\end{aligned}
$$

To decipher the rate constants we first read off the initial slope $\alpha$ and the long-term exponential decay rate $\gamma_{\mathrm{d}}$ from the pulse-escape decay curves, then constrain $\gamma_{\text {on }}$ and $\gamma_{\text {off }}$ for a given set of $\gamma_{01}$ and $\gamma_{10}$ using Equations 7 and 8 , then simulate a pulse-escape experiment by solving Equations 1 numerically, and finally identify the values of $\gamma_{01}$ and $\gamma_{10}$ that provide the best match to the experimental data.

To relate the pulse-escape kinetics of neurofilaments in the myelinated and unmyelinated axonal segments to the relative neurofilament content, we denote the average number of neurofilaments (per axonal crosssection) in the myelinated and unmyelinated segments by $N_{\mathrm{m}}$ and $N_{\mathrm{u}}$, respectively, and the corresponding average velocities by $\bar{v}_{\mathrm{m}}$ and $\bar{v}_{\mathrm{u}}$. If the neurofilament distribution is at steady state (i.e., no temporal changes in neurofilament content), then $N_{\mathrm{u}} \bar{v}_{\mathrm{u}}=N_{\mathrm{m}} \bar{v}_{\mathrm{m}}$. Thus, the observed increase in neurofilament content for the myelinated segments relative to the unmyelinated segments, $\left(N_{\mathrm{m}}-N_{\mathrm{u}}\right) / N_{\mathrm{u}}$, can be related to the average velocities by

$$
\frac{N_{m}-N_{u}}{N_{u}}=\frac{\bar{v}_{u}-\bar{v}_{m}}{\bar{v}_{m}} .
$$

\section{Results}

\section{Myelinating cultures}

To investigate the role of neurofilament transport in the myelination-dependent expansion of axon caliber, we established long-term myelinating cocultures of Schwann cells and neurons from E16.5 rat dorsal root ganglia. Figure 1 shows phase contrast images of a typical culture. Myelination is initiated by the addition of ascorbic acid, which is a cofactor in collagen biosynthesis (Eldridge et al., 1987). Before the addition of ascorbic acid, the Schwann cells proliferate rapidly and have a spread morphology. After adding ascorbic acid, the Schwann cells assume a more spindle-shaped morphology and ensheath the axons. Segments of compact myelin first appear along the axons $\sim 2$ weeks later and continue to increase in number for at least $6-8$ weeks (Monsma and Brown, 2012).

When axons are myelinated in vivo, the myelination is typically continuous, with each myelinated segment separated from the next by a node of Ranvier. In contrast, myelination in cell culture is often discontinuous, resulting in isolated myelinated 
segments flanked by unmyelinated segments (Eldridge et al., 1987; Monsma and Brown, 2012). In the present study we took advantage of this discontinuity to compare the morphology, neurofilament content, and neurofilament transport kinetics in contiguous myelinated and unmyelinated segments along single axons. In this way we were able to control for cell-to-cell variation in neurofilament expression and transport kinetics. This is important in DRG cultures because they are a heterogeneous cellular population, even when cultured in the presence of a single growth factor (nerve growth factor in our experiments; Hall et al., 1997).

\section{Axon caliber and neurofilament content}

To confirm that myelinated axons in these cultures accumulate neurofilaments and expand in caliber, we transfected neurons with GFP-tagged neurofilament protein $\mathrm{M}$ by lipofection after 4-6 weeks in culture. Fortuitously, we found that lipofection transfected the neurons but not the Schwann cells (Monsma and Brown, 2012). Six to $7 \mathrm{~d}$ later, after allowing time for the fusion protein to incorporate into neurofilaments and be transported into the axons, we performed live-cell imaging using FluoroMyelin Red to detect compact myelin (Monsma and Brown, 2012). Figure $2 A-C$ shows contiguous myelinated and unmyelinated segments along an axon expressing GFP-tagged neurofilament protein $\mathrm{M}$. We found that the axons were generally slightly brighter and slightly thicker in the myelinated axonal segment compared with the contiguous unmyelinated segment. To quantify this, we measured axon width and neurofilament intensity in contiguous myelinated and unmyelinated segments along 44 axons (Fig. $2 D-G$ ). There was considerable variation between axons, but $89 \%(n=39)$ were brighter and fatter in the myelinated segment compared with the contiguous unmyelinated segment, and the other $11 \%(n=5)$ of axons were the same or only slightly less. On average, the myelinated axonal segments were $42 \%$ brighter compared with contiguous unmyelinated segments, and the diameter was $20 \%$ greater, which corresponds to an increase in the cross-sectional area of $45 \%$. While these differences are small compared with the neurofilament accumulation and axonal expansion observed for myelinated axons in vivo, statistical analysis using a paired $t$ test revealed a high degree of confidence $\left(p=1 \times 10^{-12}\right.$ and $p=9 \times 10^{-13}$, respectively). Thus, neurofilaments accumulate locally within most myelinated axonal segments in these cultures, and this correlates with a local expansion of axonal caliber.

\section{Neurofilament transport kinetics}

To test the hypothesis that local neurofilament accumulation in myelinated axonal segments is caused by a local slowing of neurofilament transport, we analyzed the kinetics of neurofilament transport using a fluorescence photoactivation pulse-escape technique (Trivedi et al., 2007; Alami et al., 2009; Fig. 3). Myelinating cocultures were cotransfected with photoactivatable neurofilament fusion protein (PAGFP-NFM) and mCherry after 4-6 weeks in culture. The mCherry is a diffusible red fluorescent protein which served as a marker of transfection, allowing us to trace the axons of transfected cells before photoactivation. Four to $6 \mathrm{~d}$ after transfection, we performed pulse-escape analyses in contiguous myelinated and unmyelinated axonal segments. To ensure that the fluorescent filaments departing from one activated region did not contribute significantly to the other, we spaced the two activated regions at least 0.75 field of view $(\sim 500$ $\mu \mathrm{m})$ apart. In control experiments we found that there was no measurable increase in the axonal fluorescence this distance from
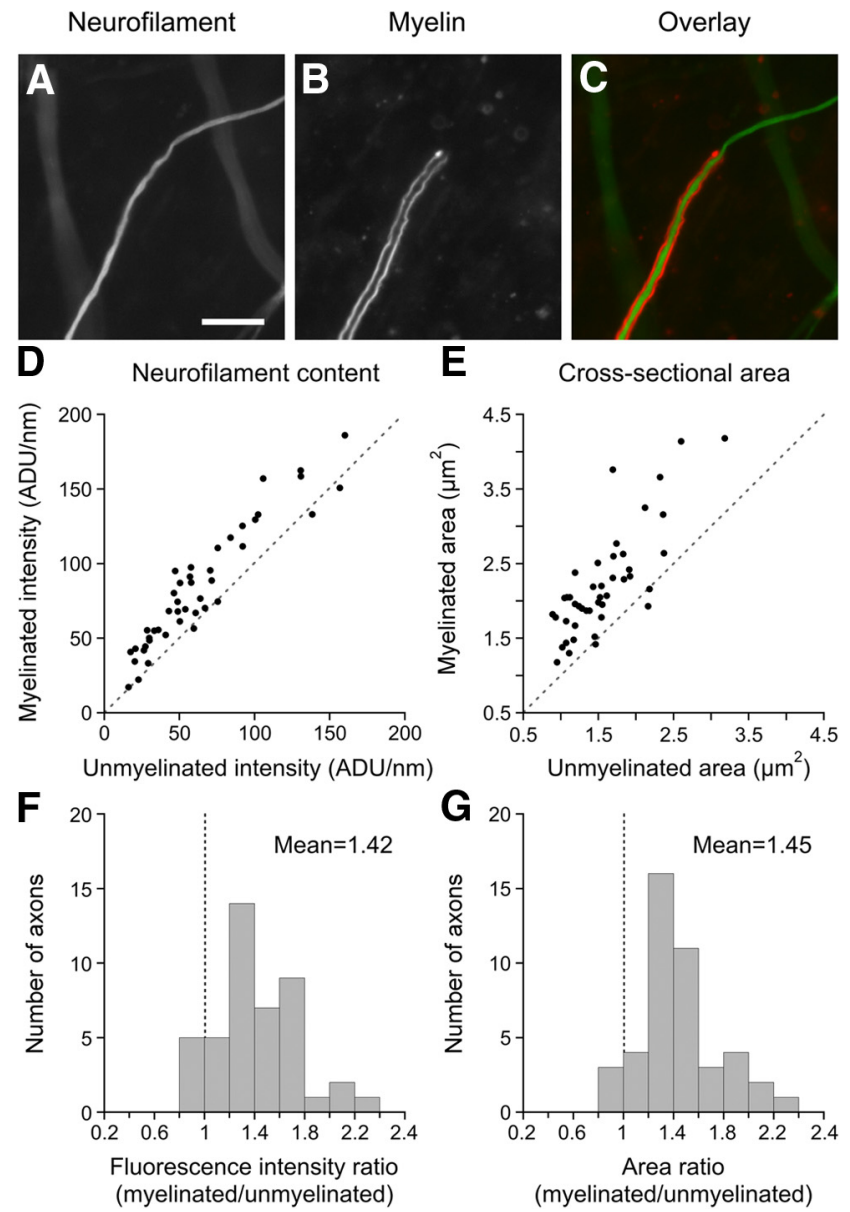

Figure 2. The caliber and neurofilament content in contiguous myelinated and unmyelinated axonal segments. Neurons were transfected with GFP-tagged neurofilament protein $M$ 6-7 d before imaging and stained with FluoroMyelin Red on the day of imaging to visualize the myelin. $\boldsymbol{A}-\boldsymbol{C}$, Live imaging of an axon expressing GFP-tagged neurofilament protein $\mathrm{M}$ and stained with FluoroMyelin Red, showing contiguous myelinated and unmyelinated segments. Note that the axon appears brighter and slightly thicker in the myelinated segment. Scale bar, $12.5 \mu \mathrm{m}$. $\boldsymbol{D}, \boldsymbol{E}$, Scatter plots of the fluorescence intensities $(\boldsymbol{D})$ and the cross-sectional areas $(\boldsymbol{E})$ of contiguous myelinated and unmyelinated axonal segments. Data from 44 axons in five different dishes from three separate cultures ranging from 28 to $40 \mathrm{~d}$ in vitro. The cross-sectional areas were estimated from the axon widths, assuming a cylindrical shape. The fluorescence intensities are a relative measure of the neurofilament content. The diagonal dashed lines represent the predicted slopes assuming no difference between the myelinated and unmyelinated segments. $\boldsymbol{F}, \boldsymbol{G}$, Histograms of the fluorescence intensity ratios $(\boldsymbol{F})$ and the axonal crosssectional area ratios $(\boldsymbol{G})$ calculated from the data in $\boldsymbol{D}$ and $\boldsymbol{E}$. The vertical dashed lines mark a ratio of 1 , which would indicate no difference between the myelinated and unmyelinated segments. The myelinated axonal segments exhibited a $42 \%$ greater neurofilament content $\left(p=1 \times 10^{-12}\right.$, paired $t$ test, $\left.n=44\right)$ and a $45 \%$ greater cross-sectional area $(p=9 \times$ $10^{-13}$, paired $t$ test, $n=44$ ) compared with their contiguous unmyelinated axonal segments.

the activated regions, and this was also consistent with predictions using computational simulations (data not shown). This is expected because the neurofilaments that leave the activation window become widely dispersed along the axon both proximal and distal to the activated region due to their stochastic and intermittent movement (Brown et al., 2005).

Figure 4 shows a representative pulse-escape experiment. As expected, the intensity of the activated fluorescence was higher in the myelinated axonal segment (Fig. $4 F$ ) compared with the contiguous unmyelinated segment (Fig. $4 E$ ) due to the local accumulation of neurofilaments in the myelinated region. Over time, the departure of neurofilaments from the activated regions resulted in a smearing of the fluorescence in both proximal and distal 
A

Activated region

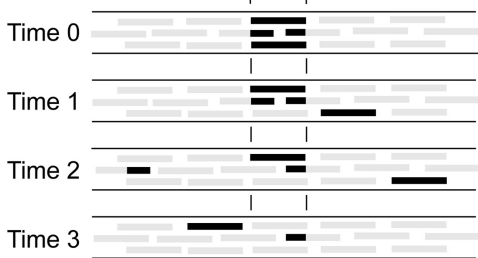

Time 3

B

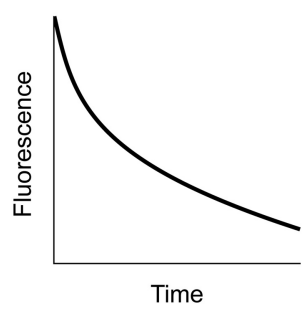

Figure 3. The pulse-escape technique. $\boldsymbol{A}$, Fluorescence photoactivation is used to create a population of fluorescent filaments in a short segment of an axon. Over time, the fluorescence in the activated region declines due to the departure of the filaments from the activated region. $\boldsymbol{B}$, The kinetics of loss of fluorescence from the activated region. Since it takes a moving filament just seconds to leave the activated region, the decay kinetics are dictated principally by the amount of time spent pausing. This technique has several advantages over singleneurofilament tracking experiments. First, it can be used on axons with high neurofilament content, where it is not presently possible to resolve single neurofilaments. Second, by analyzing the decay kinetics over a period of several hours, it is possible to analyze the long-term pausing of the filaments which dominates their transport behavior (Trivedi et al., 2007; Alami et al., 2009).

directions, which is consistent with previous observations in cultured neurons that neurofilament transport is bidirectional (Wang et al., 2000; Wang and Brown, 2001, 2010; Uchida and Brown, 2004; Alami et al., 2009; Uchida et al., 2009). However, the loss of fluorescence from these activated regions was faster in unmyelinated segments compared with contiguous myelinated segments (Fig. 4G-R).

To quantify the pulse-escape kinetics, we measured the fluorescence intensities of the activated regions for a cohort of 15 axons that were imaged at $\sim 15,30,60,90$, and 120 min after photoactivation. Figure $5 A-F$ shows six examples. There was considerable variability in the kinetics, which may reflect the heterogeneity of neuronal cell types within these cultures. However, in all cases the decay curves were biphasic and could be fitted with a double exponential decay function, as described previously for cultured neurons from both superior cervical and dorsal root ganglia (Trivedi et al., 2007; Alami et al., 2009). Given the variability in the kinetics, we performed a pairwise statistical analysis, comparing each myelinated segment with the contiguous unmyelinated segment along the same axon. On average, the decay was faster in the unmyelinated segments than in the contiguous myelinated segments, and this difference was statistically significant at all time points (Fig. 5G). Thus, neurofilaments departed the activated regions more slowly in myelinated axonal segments than in contiguous unmyelinated axon segments along the same axons, and this suggests a local slowing of neurofilament transport in the myelinated segments. Treatment of the axons with 2 $\mathrm{mm}$ iodoacetate, which is an inhibitor of glycolysis, abolished the loss of fluorescence from the activated regions completely, confirming that the fluorescence decay is due to active transport and that there is no measurable pool of diffusible neurofilament protein in these axons (Trivedi et al., 2007; Fig. 6).

\section{Computational analysis}

We have shown previously that the biphasic kinetics of departure of neurofilaments from the activated regions in pulse-escape experiments are indicative of distinct long-term and short-term pausing states (Trivedi et al., 2007). The initial more rapidly declining phase reflects the loss of neurofilaments that are in the short-term on-track pausing states at the time of activation, whereas the later, more slowly declining phase reflects the mobi-
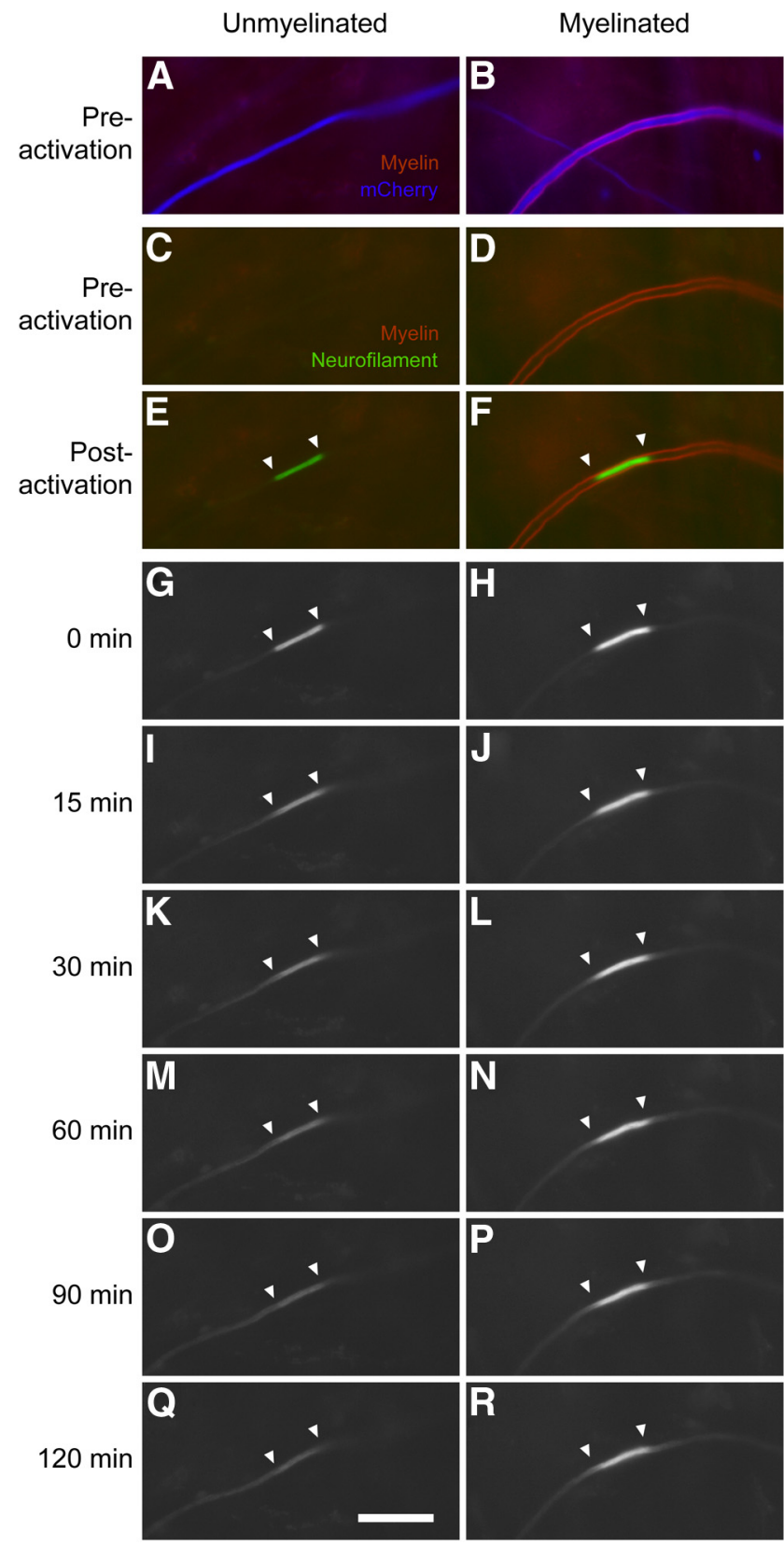

Figure 4. A pulse-escape experiment. Example of a pulse-escape experiment in contiguous unmyelinated and myelinated segments along the same axon. $\boldsymbol{A}, \boldsymbol{B}$, The mCherry fluorescence is shown in blue to distinguish it from the FluoroMyelin Red fluorescence, which is shown in red. The myelin sheath appears purple in $\boldsymbol{B}$ because of FluoroMyelin Red cross talk on the mCherry channel. C, D, The PAGFP-NFM fluorescence (green) and FluoroMyelin Red fluorescence (red) before activation. $\boldsymbol{E}, \boldsymbol{F}$, The PAGFP-NFM fluorescence ( $g r e e n)$ and FluoroMyelin Red fluorescence (red) immediately after activation ( $t=0 \mathrm{~min}$ ). We avoid $\mathrm{mCherry} \mathrm{cross} \mathrm{talk} \mathrm{on} \mathrm{the} \mathrm{FluoroMyelin}$ Red channel by using a custom filter which excites the FluoroMyelin Red with blue light, taking advantage of this dye's unusually large Stoke's shift (Monsma and Brown, 2012). Note that the activated PAGFP-NFM fluorescence is brighter in the myelinated segment than in the unmyelinated segment, which is indicative of neurofilament accumulation. $\mathbf{G}-\boldsymbol{R}$, Images of the PAGFPNFM fluorescence at $t=0,15,30,60,90$, and 120 min after photoactivation. Note that a smaller fraction of the PAGFP fluorescence departs from the myelinated segment over time, indicating that the velocity of neurofilament transport is retarded. Scale bar, $15 \mu \mathrm{m}$.

lization of neurofilaments in the long-term off-track pausing states. Thus, at early times the decay reflects a combination of the on- and off-track kinetics, whereas at later times, the decay is dominated by the off-track kinetics (see Materials and Methods). 

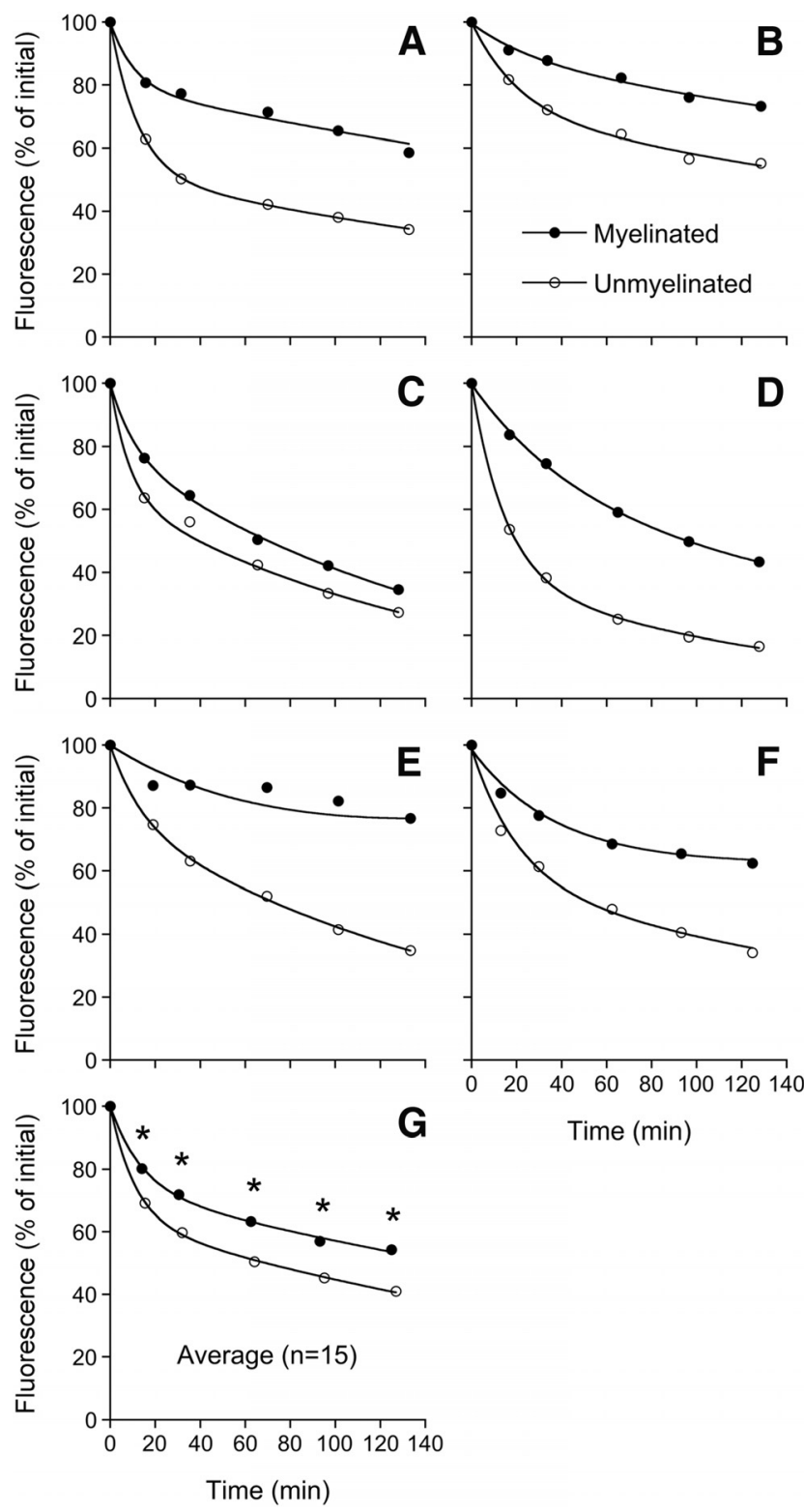

Figure 5. Pulse-escape kinetics in contiguous myelinated and unmyelinated axonal segments. The data for the myelinated and unmyelinated segments are represented by the closed and open symbols, respectively. $\boldsymbol{A}-\boldsymbol{F}$, Examples of the pulse-escape decay kinetics for contiguous myelinated and unmyelinated segments along 6 different axons. G, Average decay kinetics for contiguous myelinated and unmyelinated segments along 15 axons. The asterisks denote a statistically significant difference ( $p<0.05$, two-tailed paired $t$ test for samples with equal variances). The lines on each graph are double-exponential curve fits of the form $y=a e^{-b x}+c e^{-d x}$.

In principal, the neurofilament content of axons is dependent on the rates of synthesis, degradation, and transport. In the absence of significant synthesis or degradation of neurofilaments within these axons, local changes in transport velocity must result in local changes in neurofilament content. For example, a local increase in the velocity would result in a local decrease in the average residence time in that region and thus a local depletion of neurofilaments. Conversely, a local decrease in the velocity would result in an increase in the residence time and thus a local accumulation of neurofilaments. To determine whether the difference in the pulse-escape kinetics between contiguous myelinated and unmyelinated axonal segments can explain the neurofilament accumulation in the myelinated segments, we used the ap-

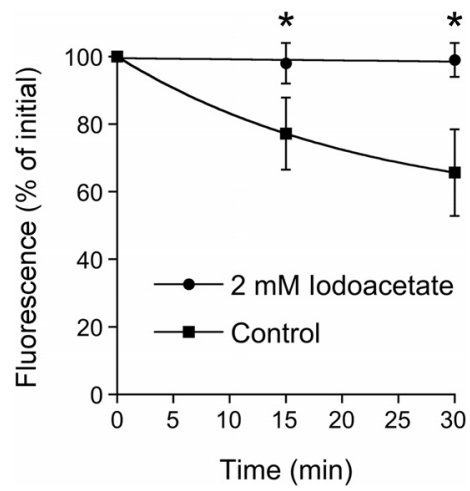

Figure 6. Neurofilament movement is blocked by metabolic inhibitors. Effect of $2 \mathrm{~mm}$ iodoacetate, which is an inhibitor of glycolysis, on the pulse-escape kinetics in unmyelinated axons. The control data are the average of 12 axons from 3 different cultures and the test data are the average of 10 axons from 3 different cultures. The error bars represent the SD about the mean. Images were acquired at 15 and 30 min after activation. For the test dataset, the axons were exposed to the inhibitor for 13-100 min before the start of the pulse-escape experiment. The asterisks denote a statistically significant difference ( $p<0.001$, one-tailed $t$ test for samples with unequal variances). The lines on each graph are double-exponential curve fits of the form $y=a e^{-b x}+c e^{-d x}$.

proach described in Materials and Methods to fit the averaged experimental data in Figure $5 G$ with our model, constraining the optimization according to Equation 10 to yield the smallest total error that was consistent with the observed $42 \%$ increase in neurofilament content, i.e., $\left(N_{\mathrm{m}}-N_{\mathrm{u}}\right) / N_{\mathrm{u}}=0.42$.

Figure $7 A$ shows that the resulting simulated pulse-escape curves produce an excellent match to the data, Figure $7 B$ shows a schematic of the six-state model of neurofilament transport that was used for these simulations, and Figure $7 C$ shows the optimized values for the rate constants $\gamma_{01}, \gamma_{10}, \gamma_{\text {on }}$, and $\gamma_{\text {off. }}$ The optimization does not yield values for the reversal rate constants $\gamma_{a r}$ and $\gamma_{r a}$ because the pulse-escape technique is blind to the direction of neurofilament movement (we track only the loss of fluorescence from the activated regions, not the direction of departure). The on-track rate constants $\gamma_{01}$ and $\gamma_{10}$ were $\sim 30 \%$ lower in the myelinated segments compared with the unmyelinated segments, whereas $\gamma_{\text {on }}$ was $\sim 25 \%$ lower and $\gamma_{\text {off }}$ was $\sim 20 \%$ higher. Knowing the values for these rate constants, we can use the solutions to our model in Equations 2-4 to predict the differences in the kinetic behavior of neurofilaments in myelinated and unmyelinated segments. Figure $7 D$ shows that the fraction of neurofilaments pausing off-track was 15\% larger in the myelinated segments and the average pausing time $\left\langle T_{\text {off }}\right\rangle$ was $33 \%$ larger. As a consequence, the mobile fraction of neurofilaments (" $\%$ moving") was $28 \%$ smaller in the myelinated segments. In addition, the average pausing time of on-track neurofilaments $\left\langle T_{\text {on }}\right\rangle$ was $44 \%$ longer in the myelinated segments. Thus, the local accumulation of neurofilaments in the myelinated axonal segments can be explained by an increase in the on-track and off-track pausing.

To calculate the average transport velocity, we need to know the balance of anterograde and retrograde movements, as seen in Equation 3. Presently this is not possible in myelinating cultures because the high neurofilament content of the axons precludes tracking single neurofilaments. However, if we assume that the filaments spend $69 \%$ of the time moving anterogradely, based on our live-cell imaging studies in cultured rat sympathetic neurons (Wang and Brown, 2001), we can estimate using Equation 3 that the average transport velocity in our myelinating cultures would be $0.22 \mathrm{~mm} / \mathrm{d}$ in the unmyelinated segments and $0.16 \mathrm{~mm} / \mathrm{d}$ in the myelinated segments. These velocities are in the range re- 
A

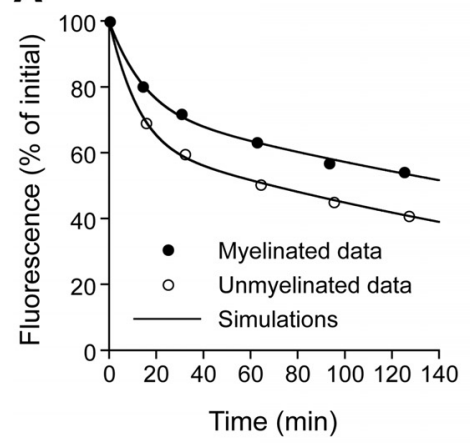

B

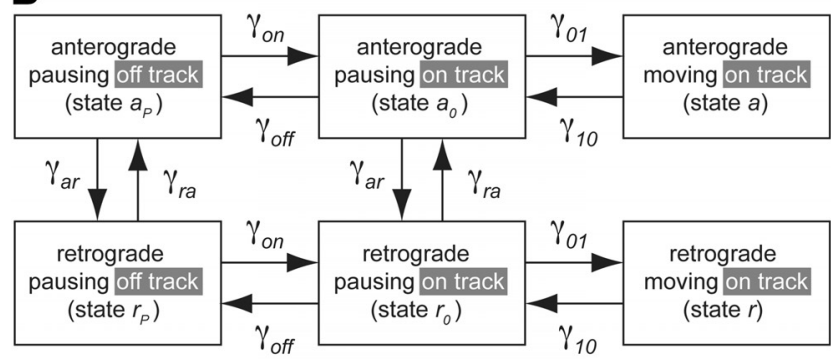

C

\begin{tabular}{|l|c|c|}
\hline Rate constant & Myelinated & Unmyelinated \\
\hline$\gamma_{01}$ & $2.0 \times 10^{-3} \mathrm{~s}^{-1}$ & $3.0 \times 10^{-3} \mathrm{~s}^{-1}$ \\
\hline$\gamma_{10}$ & $6.5 \times 10^{-2} \mathrm{~s}^{-1}$ & $8.8 \times 10^{-2} \mathrm{~s}^{-1}$ \\
\hline$\gamma_{\text {on }}$ & $4.7 \times 10^{-5} \mathrm{~s}^{-1}$ & $6.2 \times 10^{-5} \mathrm{~s}^{-1}$ \\
\hline$\gamma_{\text {off }}$ & $1.1 \times 10^{-4} \mathrm{~s}^{-1}$ & $9.1 \times 10^{-5} \mathrm{~s}^{-1}$ \\
\hline
\end{tabular}

D

\begin{tabular}{|l|c|c|}
\hline State & Myelinated & Unmyelinated \\
\hline$\%$ on track $\rho_{\text {on }} \equiv \rho_{\mathrm{a}}+\rho_{\mathrm{r}}+\rho_{\mathrm{a} 0}+\rho_{\mathrm{r} 0}$ & $32 \%$ & $41 \%$ \\
\hline$\%$ off track $\rho_{\text {off }} \equiv \rho_{\text {ap }}+\rho_{\text {rp }}$ & $68 \%$ & $59 \%$ \\
\hline$\%$ moving $\rho_{\text {move }} \equiv \rho_{\text {a }}+\rho_{\mathrm{r}}$ & $0.94 \%$ & $1.3 \%$ \\
\hline Off-track pause $<T_{\text {off }}>=1 / \gamma_{\text {on }}$ & $360 \mathrm{~min}$ & $270 \mathrm{~min}$ \\
\hline On-track pause $<T_{\text {on }}>=1 /\left(\gamma_{01}+\gamma_{\text {off }}\right)$ & $7.9 \mathrm{~min}$ & $5.5 \mathrm{~min}$ \\
\hline Velocity $\bar{v}$ & $0.16 \mathrm{~mm} \cdot \mathrm{d}^{-1}$ & $0.22{\mathrm{~mm} . \mathrm{d}^{-1}}$ \\
\hline
\end{tabular}

Figure 7. Modeling the pulse-escape kinetics. $\boldsymbol{A}$, Average decay kinetics from Figure $5 G$. The data for the myelinated and unmyelinated segments are represented by the closed and open symbols, respectively. The curves represent optimized computational simulations constrained to match the $42 \%$ increase in neurofilament content in the myelinated segments (Fig. 2). $\boldsymbol{B}$, Schematic of the six-state model of neurofilament transport from Jung and Brown (2009) showing the rate constants that govern the transitions between the moving and pausing states. C, Table of the rate constants for the optimized simulations that are shown in A. D, Table of the kinetic predictions of the model based on the optimized rate constants, calculated using the expressions in Equations 2- 4 in Materials and Methods.

ported for slow axonal transport of neurofilaments in peripheral nerves in vivo (Brown, 2009).

\section{Discussion}

We have used myelinating cocultures to investigate the relationship between neurofilament transport and axon caliber. We found that the axons in these cultures expand locally in regions where they are myelinated and that this radial expansion correlates with a local accumulation of neurofilaments and a local slowing of neurofilament transport. These findings suggest that
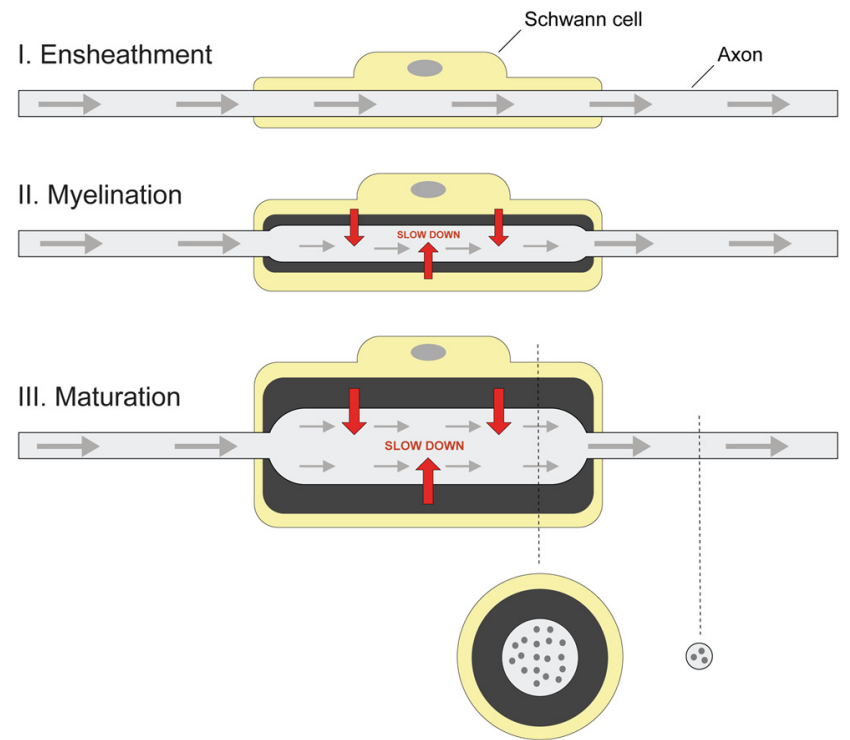

Figure 8. Local regulation of axonal caliber by myelinating cells. Schematic diagram illustrating our hypothesis for the contribution of neurofilament transport to the local expansion of axon caliber in myelinated axons. For simplicity, this diagram shows a single Schwann cell. I, Initially, the unmyelinated axon is ensheathed by the Schwann cell. II, After the Schwann cell begins to myelinate the axon, it signals to the axon via a paracrine or juxtacrine (i.e., contactdependent) mechanism to slow down neurofilament transport by increasing the proportion of the time that the neurofilaments spend pausing. When neurofilaments enter the myelinated axonal segment from the flanking unmyelinated segments, this increases their residence time in that portion of the axon, causing them to accumulate locally, much as the traffic density on a highway increases when the speed of the vehicles slows. This local accumulation of neurofilaments drives a distension of the axonal plasma membrane due to the space-filling properties of these polymers, resulting in an expansion of axonal cross-sectional area. III, The stronger the signal the more extensive the slowing, and consequently the greater the extent of axonal expansion. The vertical dashed lines indicate the location of two cross-sectional views. The gray dots within the axonal cross-sections represent neurofilaments, which are more numerous in the myelinated segment. As the axon matures, we assume that there must be a feedback loop that ensures that the average velocity of neurofilament transport does not continue to decrease once the axon has reached the desired caliber. In the mature axon the number of filaments entering the myelinated segment would be expected to be balanced exactly by the number leaving, establishing a stable, steady-state morphology for that portion of the axon. In this way, myelinating cells may regulate axonal morphology by locally modulating the kinetics of neurofilament transport.

Schwann cells can signal locally to axons to slow neurofilament transport, leading to a local accumulation of these polymers and a local expansion of axonal caliber. Thus, our data demonstrate that myelinating cells can modulate axonal morphology by locally regulating neurofilament transport (Fig. 8).

Our data do not address the mechanism by which myelinating glia regulate neurofilament transport, but one possibility is phosphorylation of the tail domains of neurofilament proteins $M$ and $\mathrm{H}$, which form the neurofilament side-arms. Phosphorylation of these domains is upregulated in axons upon myelination (Nixon et al., 1994; Sanchez et al., 1996, 2000; Starr et al., 1996), correlates with a slowing of neurofilament transport during development (Watson et al., 1989; Archer et al., 1994; Yabe et al., 2001; Jung and Shea, 2004), and has also been reported to increase neurofilament pausing in cultured neurons (Ackerley et al., 2000, 2003). Phosphorylation of these domains also increases the extensibility of neurofilament side-arms in vitro (Aranda-Espinoza et al., 2002; Kumar and Hoh, 2004; Zhulina and Leermakers, $2007 \mathrm{a}, \mathrm{b})$ and correlates with an increase in the spacing between neurofilaments in axons (de Waegh et al., 1992; Martin et al., 1999). Thus, neurofilament phosphorylation may contribute to 
the expansion of axonal caliber in two ways, by increasing both the number and space-filling properties of these polymers. However, the role of neurofilament phosphorylation in the regulation of neurofilament transport and spacing in vivo is controversial and remains unresolved (Shea et al., 2003; Yuan et al., 2006; Garcia et al., 2009; Barry et al., 2012).

To act locally, we assume that any signaling by myelinating cells to slow neurofilament transport must be juxtacrine (i.e., contact dependent) or paracrine in nature. There is extensive local and bidirectional signaling between Schwann cells and axons that is critical for the regulation of myelination and for the metabolic (and possibly also trophic) support of axons, although many of the signaling pathways involved are not well understood (Nave and Trapp, 2008; Pereira et al., 2012). Myelin-associated glycoprotein (MAG) is a possible candidate for transducing signals that might regulate the radial expansion of myelinated axons. MAG is a transmembrane protein that is expressed exclusively in myelinating Schwann cells and is enriched in the adaxonal membrane where it could interact with axonal receptors (Schnaar and Lopez, 2009). Axon caliber and the number, phosphorylation, and spacing of neurofilaments are all reduced in axons of MAG knock-out mice (Yin et al., 1998), and MAG also stimulates the phosphorylation of the tail domains of neurofilament proteins $\mathrm{M}$ and $\mathrm{H}$ in PC12 cells and cultured DRG neurons (Dashiell et al., 2002). However, MAG cannot be the full story because the average reduction in axonal caliber in MAG knock-out mice is $<10 \%$, which is a relatively modest change.

The number of neurofilaments in axons is determined not only by the kinetics of neurofilament transport but also by the rate of neurofilament synthesis in the soma (Hsieh et al., 1994; Hoffman, 1995), and many studies have suggested that changes in neurofilament gene expression, transport, and packing density all contribute to the expansion of axon caliber (Hoffman et al., 1987; Muma et al., 1991; Hsieh et al., 1994; Nixon et al., 1994; Hoffman, 1995; Sanchez et al., 1996, 2000). However, changes in gene expression in the soma must affect the entire axon, so they cannot explain local changes in neurofilament number and axon caliber such as what we have observed in isolated myelinated axonal segments. Therefore, it seems likely that neurofilament gene expression sets the global baseline neurofilament content of axons, whereas changes in neurofilament packing density and transport velocity modulate neurofilament content locally to either increase or decrease the axonal caliber above or below that level. This is consistent with our data, which show that the baseline neurofilament content and caliber of the axons in our cultures varied widely, yet in almost all cases, myelination resulted in a further increase locally within the myelinated axonal segment (Fig. 2D).

The earliest demonstration of the local effect of Schwann cells on axon caliber was obtained by Aguayo and colleagues using the Trembler mouse, which exhibits peripheral hypomyelination due to a mutation in the myelin protein PMP-22 (Aguayo et al., 1977; Suter et al., 1992). By grafting sciatic nerve segments from Trembler mice into wild-type mouse sciatic nerves, these authors showed that local hypomyelination of axons resulted in a local decrease in caliber (Bray et al., 1981). Subsequently, Brady and colleagues showed that this local decrease in axon caliber was accompanied by a local decrease in neurofilament phosphorylation and a local increase in neurofilament packing density, but also (using radioisotopic pulse-labeling) by a local decrease in the velocity of neurofilament transport and no decrease in neurofilament number (de Waegh and Brady, 1990, 1991; de Waegh et al., 1992). This slowing of neurofilament transport in a region of hypomyelination is the opposite of what we would expect based on our present data. However, a somewhat different result was obtained using Shiverer mice, which lack CNS myelin due to a null mutation in the gene for myelin basic protein. Brady and colleagues showed that these mice exhibit changes in neurofilament phosphorylation and packing density similar to those observed in the Trembler nerve grafts, but also an increase in the velocity of neurofilament transport and a decrease in neurofilament number (Brady et al., 1999; Witt and Brady, 2000). A decrease in neurofilament number has also been reported to accompany the decrease in axon caliber in hypomyelinated human sural nerve (Nukada and Dyck, 1984). Partial rescue of the myelination defect in Shiverer mice by transgenic expression of myelin basic protein abolished the increase in neurofilament transport velocity (Brady et al., 1999). A possible explanation for these data is that axons in the Trembler mice actually experience cycles of abortive myelination, whereas the axons in the Shiverer mice are never myelinated (Witt and Brady, 2000). Thus, the glial signaling in Trembler nerves may be quite different from that encountered along unmyelinated axonal segments in our cultures. Regardless of the explanation, however, the complex phenotypes of these mutants do indicate that the transport and space-filling properties of neurofilaments can be regulated independently and that both can influence axonal caliber.

Our prior studies on the axonal transport of neurofilaments suggest a stop-and-go model in which the velocity of slow axonal transport is a temporal summation of rapid movements interrupted by prolonged pauses (Brown, 2000, 2009; Brown et al., 2005; Trivedi et al., 2007; Jung and Brown, 2009). According to this model, the average velocity of neurofilament transport is very sensitive to changes in both the directionality and pausing behavior of the filaments (Jung and Brown, 2009). Our computational modeling of the pulse-escape kinetics indicates that the slowing of neurofilament transport in isolated myelinated axonal segments could be explained by a local increase in the average time spent pausing. However, a limitation of the pulse-escape approach is that it does not yield information about the directionality of neurofilament transport (see Results). Given the low frequency of neurofilament reversals observed in our prior livecell imaging studies (Uchida and Brown, 2004), it is unclear if modulating reversals alone could produce a sufficiently localized accumulation of neurofilaments to explain our experimental data. To test this will require new experimental strategies that can quantify the directionality of neurofilament transport in axons that have abundant neurofilaments.

\section{References}

Ackerley S, Grierson AJ, Brownlees J, Thornhill P, Anderton BH, Leigh PN, Shaw CE, Miller CC (2000) Glutamate slows axonal transport of neurofilaments in transfected neurons. J Cell Biol 150:165-176. CrossRef Medline

Ackerley S, Thornhill P, Grierson AJ, Brownlees J, Anderton BH, Leigh PN, Shaw CE, Miller CC (2003) Neurofilament heavy chain side arm phosphorylation regulates axonal transport of neurofilaments. J Cell Biol 161: 489-495. CrossRef Medline

Aguayo AJ, Attiwell M, Trecarten J, Perkins S, Bray GM (1977) Abnormal myelination in transplanted Trembler mouse Schwann cells. Nature 265: 73-75. CrossRef Medline

Alami NH, Jung P, Brown A (2009) Myosin Va increases the efficiency of neurofilament transport by decreasing the duration of long-term pauses. J Neurosci 29:6625-6634. CrossRef Medline

Aranda-Espinoza H, Carl P, Leterrier JF, Janmey P, Discher DE (2002) Domain unfolding in neurofilament sidearms: effects of phosphorylation and ATP. FEBS Lett 531:397-401. CrossRef Medline

Archer DR, Watson DF, Griffin JW (1994) Phosphorylation-dependent immunoreactivity of neurofilaments and the rate of slow axonal transport in 
the central and peripheral axons of the rat dorsal root ganglion. J Neurochem 62:1119-1125. Medline

Barry DM, Stevenson W, Bober BG, Wiese PJ, Dale JM, Barry GS, Byers NS, Strope JD, Chang R, Schulz DJ, Shah S, Calcutt NA, Gebremichael Y, Garcia ML (2012) Expansion of neurofilament medium C terminus increases axonal diameter independent of increases in conduction velocity or myelin thickness. J Neurosci 32:6209-6219. CrossRef Medline

Brady ST, Witt AS, Kirkpatrick LL, de Waegh SM, Readhead C, Tu PH, Lee VMY (1999) Formation of compact myelin is required for maturation of the axonal cytoskeleton. J Neurosci 19:7278-7288. Medline

Bray GM, Rasminsky M, Aguayo AJ (1981) Interactions between axons and their sheath cells. Annu Rev Neurosci 4:127-162. CrossRef Medline

Brown A (2000) Slow axonal transport: stop and go traffic in the axon. Nat Rev Mol Cell Biol 1:153-156. CrossRef Medline

Brown A (2003) Axonal transport of membranous and nonmembranous cargoes: a unified perspective. J Cell Biol 160:817-821. CrossRef Medline

Brown A (2009) Slow axonal transport. In: Encyclopedia of Neuroscience (Squire LR, ed), pp 1-9. Oxford: Academic.

Brown A, Wang L, Jung P (2005) Stochastic simulation of neurofilament transport in axons: the "stop-and-go" hypothesis. Mol Biol Cell 16:42434255. CrossRef Medline

Cleveland DW, Monteiro MJ, Wong PC, Gill SR, Gearhart JD, Hoffman PN (1991) Involvement of neurofilaments in the radial growth of axons. J Cell Sci Suppl 15:85-95. Medline

Dashiell SM, Tanner SL, Pant HC, Quarles RH (2002) Myelin-associated glycoprotein modulates expression and phosphorylation of neuronal cytoskeletal elements and their associated kinases. J Neurochem 81:12631272. CrossRef Medline

de Waegh S, Brady ST (1990) Altered slow axonal transport and regeneration in a myelin-deficient mutant mouse: the trembler as an in vivo model for Schwann cell-axon interactions. J Neurosci 10:1855-1865. Medline

de Waegh SM, Brady ST (1991) Local control of axonal properties by Schwann cells: neurofilaments and axonal transport in homologous and heterologous nerve grafts. J Neurosci Res 30:201-212. Medline

de Waegh SM, Lee VM, Brady ST (1992) Local modulation of neurofilament phosphorylation, axonal caliber, and slow axonal transport by myelinating Schwann cells. Cell 68:451-463. CrossRef Medline

Duncan D (1934) The importance of diameter as a factor in myelination. Science 79:363. CrossRef Medline

Eldridge CF, Bunge MB, Bunge RP, Wood PM (1987) Differentiation of axon-related Schwann cells in vitro. I. Ascorbic acid regulates basal lamina assembly and myelin formation. J Cell Biol 105:1023-1034. CrossRef Medline

Fex Svenningsen A, Shan WS, Colman DR, Pedraza L (2003) Rapid method for culturing embryonic neuron-glial cell cocultures. J Neurosci Res 72: 565-573. CrossRef Medline

Friede RL, Samorajski T (1970) Axon caliber related to neurofilaments and microtubules in sciatic nerve fibers of rats and mice. Anat Rec 167:379387. CrossRef Medline

Friede RL, Miyaghishi T, Hu KH (1971) Axon calibre, neurofilaments, microtubules, sheath thickness and cholesterol in cat optic nerve fibres. J Anat 108:365-373. Medline

Garcia ML, Rao MV, Fujimoto J, Garcia VB, Shah SB, Crum J, Gotow T, Uchiyama Y, Ellisman M, Calcutt NA, Cleveland DW (2009) Phosphorylation of highly conserved neurofilament medium KSP repeats is not required for myelin-dependent radial axonal growth. J Neurosci 29:12771284. CrossRef Medline

Hall AK, Ai X, Hickman GE, MacPhedran SE, Nduaguba CO, Robertson CP (1997) The generation of neuronal heterogeneity in a rat sensory ganglion. J Neurosci 17:2775-2784. Medline

Hartline DK, Colman DR (2007) Rapid conduction and the evolution of giant axons and myelinated fibers. Curr Biol 17:R29-R35. CrossRef Medline

Hisanaga S, Hirokawa N (1988) Structure of the peripheral domains of neurofilaments revealed by low angle rotary shadowing. J Mol Biol 202:297305. CrossRef Medline

Hoffman PN (1995) The synthesis, axonal transport, and phosphorylation of neurofilaments determine axonal caliber in myelinated nerve fibers. Neuroscientist 1:76-83. CrossRef

Hoffman PN, Lasek RJ, Griffin JW, Price DL (1983) Slowing of the axonal transport of neurofilament proteins during development. J Neurosci 3:1694-1700. Medline
Hoffman PN, Griffin JW, Price DL (1984) Control of axonal caliber by neurofilament transport. J Cell Biol 99:705-714. CrossRef Medline

Hoffman PN, Thompson GW, Griffin JW, Price DL (1985a) Changes in neurofilament transport coincide temporally with alterations in the caliber of axons in regenerating motor fibers. J Cell Biol 101:1332-1340. CrossRef Medline

Hoffman PN, Griffin JW, Gold BG, Price DL (1985b) Slowing of neurofilament transport and the radial growth of developing nerve fibers. J Neurosci 5:2920-2929. Medline

Hoffman PN, Cleveland DW, Griffin JW, Landes PW, Cowan NJ, Price DL (1987) Neurofilament gene expression: a major determinant of axonal caliber. Proc Natl Acad Sci U S A 84:3472-3476. CrossRef Medline

Hsieh ST, Kidd GJ, Crawford TO, Xu Z, Lin WM, Trapp BD, Cleveland DW, Griffin JW (1994) Regional modulation of neurofilament organization by myelination in normal axons. J Neurosci 14:6392-6401. Medline

Jung C, Shea TB (2004) Neurofilament subunits undergo more rapid translocation within retinas than in optic axons. Brain Res Mol Brain Res 122:188-192. CrossRef Medline

Jung P, Brown A (2009) Modeling the slowing of neurofilament transport along the mouse sciatic nerve. Phys Biol 6:046002. CrossRef Medline

Kumar S, Hoh JH (2004) Modulation of repulsive forces between neurofilaments by sidearm phosphorylation. Biochem Biophys Res Commun 324: 489-496. CrossRef Medline

Martin R, Door R, Ziegler A, Warchol W, Hahn J, Breitig D (1999) Neurofilament phosphorylation and axon diameter in the squid giant fibre system. Neuroscience 88:327-336. CrossRef Medline

Matthews MA (1968) An electron microscopic study of the relationship between axon diameter and the initiation of myelin production in the peripheral nervous system. Anat Rec 161:337-351. CrossRef Medline

Matthews MA, Duncan D (1971) A quantitative study of morphological changes accompanying the initiation and progress of myelin production in the dorsal funiculus of the rat spinal cord. J Comp Neurol 142:1-22. CrossRef Medline

Monsma PC, Brown A (2012) FluoroMyelin Red is a bright, photostable and non-toxic fluorescent stain for live imaging of myelin. J Neurosci Methods 209:344-350. CrossRef Medline

Mukhopadhyay R, Kumar S, Hoh JH (2004) Molecular mechanisms for organizing the neuronal cytoskeleton. Bioessays 26:1017-1025. CrossRef Medline

Muma NA, Slunt HH, Hoffman PN (1991) Postnatal increases in neurofilament gene expression correlate with the radial growth of axons. J Neurocytol 20:844-854. CrossRef Medline

Nave KA, Trapp BD (2008) Axon-glial signaling and the glial support of axon function. Annu Rev Neurosci 31:535-561. CrossRef Medline

Nixon RA, Paskevich PA, Sihag RK, Thayer CY (1994) Phosphorylation on carboxyl terminus domains of neurofilament proteins in retinal ganglion cell neurons in vivo: influences on regional neurofilament accumulation, interneurofilament spacing, and axon caliber. J Cell Biol 126:1031-1046. CrossRef Medline

Nukada H, Dyck PJ (1984) Decreased axon caliber and neurofilaments in hereditary motor and sensory neuropathy, type I. Ann Neurol 16:238241. CrossRef Medline

Pannese E, Ledda M, Matsuda S (1988) Nerve fibres with myelinated and unmyelinated portions in dorsal spinal roots. J Neurocytol 17:693-700. CrossRef Medline

Pereira JA, Lebrun-Julien F, Suter U (2012) Molecular mechanisms regulating myelination in the peripheral nervous system. Trends Neurosci 35: 123-134. CrossRef Medline

Perrot R, Eyer J (2010) Crosstalks between myelinating cells and the axonal cytoskeleton. In: Cytoskeleton of the nervous system (Nixon RA, Yuan A, eds), pp 603-626. New York: Springer.

Perrot R, Lonchampt P, Peterson AC, Eyer J (2007) Axonal neurofilaments control multiple fiber properties but do not influence structure or spacing of nodes of Ranvier. J Neurosci 27:9573-9584. CrossRef Medline

Roy S, Coffee P, Smith G, Liem RKH, Brady ST, Black MM (2000) Neurofilaments are transported rapidly but intermittently in axons: implications for slow axonal transport. J Neurosci 20:6849-6861. Medline

Sakaguchi T, Okada M, Kitamura T, Kawasaki K (1993) Reduced diameter and conduction velocity of myelinated fibers in the sciatic nerve of a neurofilament-deficient mutant quail. Neurosci Lett 153:65-68. CrossRef Medline

Sanchez I, Hassinger L, Paskevich PA, Shine HD, Nixon RA (1996) Oligo- 
dendroglia regulate the regional expansion of axon caliber and local accumulation of neurofilaments during development independently of myelin formation. J Neurosci 16:5095-5105. Medline

Sanchez I, Hassinger L, Sihag RK, Cleveland DW, Mohan P, Nixon RA (2000) Local control of neurofilament accumulation during radial growth of myelinating axons in vivo: selective role of site-specific phosphorylation. J Cell Biol 151:1013-1024. CrossRef Medline

Schmidt MM, Dringen R (2009) Differential effects of iodoacetamide and iodoacetate on glycolysis and glutathione metabolism of cultured astrocytes. Front Neuroenergetics 1:1. Medline

Schnaar RL, Lopez PH (2009) Myelin-associated glycoprotein and its axonal receptors. J Neurosci Res 87:3267-3276. CrossRef Medline

Shaner NC, Campbell RE, Steinbach PA, Giepmans BN, Palmer AE, Tsien RY (2004) Improved monomeric red, orange and yellow fluorescent proteins derived from Discosoma sp. red fluorescent protein. Nat Biotechnol 22:1567-1572. CrossRef Medline

Shea TB, Jung C, Pant HC (2003) Does neurofilament phosphorylation regulate axonal transport? Trends Neurosci 26:397-400. CrossRef Medline

Starr R, Attema B, DeVries GH, Monteiro MJ (1996) Neurofilament phosphorylation is modulated by myelination. J Neurosci Res 44:328-337. CrossRef Medline

Suter U, Welcher AA, Ozcelik T, Snipes GJ, Kosaras B, Francke U, BillingsGagliardi S, Sidman RL, Shooter EM (1992) Trembler mouse carries a point mutation in a myelin gene. Nature 356:241-244. CrossRef Medline

Trivedi N, Jung P, Brown A (2007) Neurofilaments switch between distinct mobile and stationary states during their transport along axons. J Neurosci 27:507-516. CrossRef Medline

Uchida A, Brown A (2004) Arrival, reversal and departure of neurofilaments at the tips of growing axons. Mol Biol Cell 15:4215-4225. CrossRef Medline

Uchida A, Alami NH, Brown A (2009) Tight functional coupling of kinesin-1A and dynein motors in the bidirectional transport of neurofilaments. Mol Biol Cell 20:4997-5006. CrossRef Medline

Wang L, Brown A (2001) Rapid intermittent movement of axonal neurofilaments observed by fluorescence photobleaching. Mol Biol Cell 12: 3257-3267. CrossRef Medline

Wang L, Brown A (2010) A hereditary spastic paraplegia mutation in kine-
sin-1A/KIF5A disrupts neurofilament transport. Molecular Neurodegeneration 5:52. CrossRef Medline

Wang L, Ho CL, Sun D, Liem RKH, Brown A (2000) Rapid movement of axonal neurofilaments interrupted by prolonged pauses. Nat Cell Biol 2:137-141. CrossRef Medline

Watson DF, Griffin JW, Fittro KP, Hoffman PN (1989) Phosphorylationdependent immunoreactivity of neurofilaments increases during axonal maturation and beta, beta'-iminodipropionitrile intoxication. J Neurochem 53:1818-1829. CrossRef Medline

Waxman SG (1980) Determinants of conduction velocity in myelinated nerve fibers. Muscle Nerve 3:141-150. CrossRef Medline

Windebank AJ, Wood P, Bunge RP, Dyck PJ (1985) Myelination determines the caliber of dorsal root ganglion neurons in culture. J Neurosci 5:15631569. Medline

Witt A, Brady ST (2000) Unwrapping new layers of complexity in axon/glial relationships. Glia 29:112-117. CrossRef Medline

Yabe JT, Chylinski T, Wang FS, Pimenta A, Kattar SD, Linsley MD, Chan WK, Shea TB (2001) Neurofilaments consist of distinct populations that can be distinguished by C-terminal phosphorylation, bundling, and axonal transport rate in growing axonal neurites. J Neurosci 21:2195-2205. Medline

Yin X, Crawford TO, Griffin JW, Tu P, Lee VM, Li C, Roder J, Trapp BD (1998) Myelin-associated glycoprotein is a myelin signal that modulates the caliber of myelinated axons. J Neurosci 18:1953-1962. Medline

Yuan A, Nixon RA, Rao MV (2006) Deleting the phosphorylated tail domain of the neurofilament heavy subunit does not alter neurofilament transport rate in vivo. Neurosci Lett 393:264-268. CrossRef Medline

Zhu Q, Couillard-Despres S, Julien JP (1997) Delayed maturation of regenerating myelinated axons in mice lacking neurofilaments. Exp Neurol 148:299-316. CrossRef Medline

Zhulina EB, Leermakers FA (2007a) A self-consistent field analysis of the neurofilament brush with amino-acid resolution. Biophys J 93:14211430. CrossRef Medline

Zhulina EB, Leermakers FA (2007b) Effect of the ionic strength and $\mathrm{pH}$ on the equilibrium structure of a neurofilament brush. Biophys J 93:14521463. CrossRef Medline 